\title{
Penyuluhan dan Pendampingan Pemetaan Partisipatif di Kecamatan Anggeraja Kabupaten Enrekang
}

\author{
Ihsan*, Abdul Rachman Rasyid, Laode Muhammad Asfan Mujahid, Sri Aliah Ekawati, Suci \\ Anugrah Yanti \\ Departemen Perencanaan Wilayah dan Kota, Fakultas Teknik Universitas Hasanuddin* \\ ace.ihsan@gmail.com*
}

\begin{abstract}
Abstrak
Peta disajikan untuk memberikan informasi-informasi berupa batas wilayah, sarana prasarana, bangunan, penggunaan lahan dan jalan. Batas wilayah sebagai salah satu unsur peta desa sehingga perlu dipetakan secara detail sebagai dokumen dalam perencanaan pembangunan. Kabupaten Enrekang yang memiliki kawasanya sebagian besar merupakan kawasan lindung masih sangat minim pada kepemilikan dokumen pemetaan. Masyarakat pun masih belum memiliki pengetahuan mengenai pemetaan ini sehingga masalah batas kawasan, batas wilayah mamupun batas penggunaan lahan masih menjadi pemicu masalah di masyarakat. Pemetaan partisipatif merupakan metode yang dibutuhkan dalam rangka penyediaan informasi spasial sehingga proses pemetaan dan peta yang dihasilkan bertujuan untuk kepentingan masyarakat. Dalam hal ini, kegiatan penyuluhan dan pendampingan merupakan awal dari pembangunan kompetensi dan kapasitas bagi masyarakat dalam pembuatan dokumen pemetaan di Kabupaten Enrekang. Diharapkan kegiatan pengabdian kepada masyarakat ini berlanjut dalam kegiatan kemitraan antara Unhas dengan Pemda Kabupaten Enrekang, baik dalam pelatihan-pelatihan, pendidikan formal magister pengembangan wilayah dan kota, serta pendampingan perencanaan dan pelaksanaan pengembangan wilayah Kabupaten Enrekang, sejalan dengan kegiatan tridharma perguruan tinggi.
\end{abstract}

Kata Kunci: Peta; partisipatif; penyuluhan; pengabdian masyarakat; Kabupaten Enrekang.

\begin{abstract}
Maps are presented to provide information in the form of boundaries, facilities, buildings, land use and roads. Regional boundaries are one element of the village map so that it needs to be mapped in detail as a document in development planning. Enrekang Regency, which has a majority of its elders as protected areas, is still very limited in the ownership of mapping documents. The community still does not have knowledge about this mapping so that the problem of regional boundaries, regional boundaries and land use limits is still a trigger for problems in the community. Participatory mapping is a method that is needed in order to provide spatial information so that the mapping process and the resulting map are aimed at the interests of the community. In this case, counseling and mentoring activities are the beginning of the development of competence and capacity for the community in making mapping documents in Enrekang District. It is expected that this community service activity will continue in partnership activities between Unhas and the Enrekang District Government, both in training, formal education in regional and city development master programs, and assistance in planning and implementing the development of Enrekang Regency, in line with the tridharma activities of higher education.
\end{abstract}

Keywords: Map; participatory; counseling; community service; Enrekang Regency.

\section{Pendahuluan}

Secara umum negara Indonesia dalam pembangunannya tidak lepas dari peraturan dan perundangan di Indonesia yaitu antara lain adalah sebagaimana diamanatkan amanat UUD 1945 Pasal 33 Ayat 3, 4 dan 5, pengelolaan sumberdaya alam memerlukan peta dan informasi geospasial untuk menunjukkan lokasi dan sebaran potensinya. Hal ini untuk menjalankan amanat UUD 1945 Pasal 25A, dan Pasal 30 Ayat 2. Setiap Warga Negara Indonesia berhak mencari, 
memperoleh, memiliki, menyimpan, mengolah, dan menyampaikan peta dan informasi geospasial untuk mengembangkan pribadi dan lingkungan sosialnya dengan menggunakan segala jenis saluran yang tersedia. Hal ini diamanatkan pada UUD 45 pasal 28F, bahwa agar setiap orang berhak mendapatkan manfaat yang optimal dari kemajuan ilmu dan teknologi informasi geospasial serta agar negara dapat maksimal memajukan ilmu dan teknologi informasi geospasial demi kemajuan peradaban serta kesejahteraan umat manusia.

Peraturan Pemerintah nomor 78 tahun 2007 tentang Tata Cara Pembentukan, Penghapusan dan Penggabungan Daerah, pasal 1 ayat 6 menyebutkan:" Daerah otonom, selanjutnya disebut daerah, adalah kesatuan masyarakat hukum yang mempunyai batas-batas wilayah, yang berwenang mengatur dan mengurus urusan pemerintahan dan kepentingan masyarakat setempat menurut prakarsa sendiri berdasarkan aspirasi masyarakat dalam sistem Negara Kesatuan Republik Indonesia".

Kondisi kabupaten Enrekang yang saat ini memperlihatkan kawasan lindung yang cukup luas. Namun, diketahui masyarakat masih kurang memiliki pengetahuan informasi geospasial mengenai tapal batas kawasan. Pemetaan partisipatif merupakan metode alternatif dalam rangka penyediaan informasi spasial. Dengan adanya perundangan-undangan yang mengatur, maka masyarakat dapat berpartisipasi dalam pembuatan peta di kawasan mereka sendiri. Karena selama ini peta menjadi acuan tata ruang dalam pelaksanaan pembangunan nasional. Masyarakat juga bisa membuat peta untuk kepentingan pembelajaran budaya lokal dan pewarisan pengetahuan bagi generasi selanjutnya, terutama yang berhubungan dengan sumber daya alam dan potensi yang ada.

\section{Analisis Situasi}

Kabupaten Enrekang secara georafis adalah kabupaten yang terletak di sebelah utara Propinsi Sulawesi Selatan dengan jarak $\pm 240 \mathrm{Km}$ yang berupa wilayah pegunungan dataran tinggi, dengan luas wilayah 1.786,01 Km2 (lebih kurang 2,86\% dari luas Propinsi Sulawesi Selatan). Secara administratif, Kabupaten Enrekang terdiri dari 12 Kecamatan, 112 Desa dan 17 Kelurahan. Wilayah kabupaten Enrekang berbatasan langsung dengan Kabupaten Tana Toraja (Utara), Kabupaten Luwu (Timur), Kabupaten Sidrap (Selatan) dan Kabupaten Pinrang (Barat). Kecamatan Anggeraja merupakan salah satu kecamatan yang berada dalam wilayah administrasi Kabupaten Enrekang.

Pemetaan Partisipatif adalah satu metode pemetaan yang menempatkan masyarakat sebagai pelaku pemetaan wilayahnya, sekaligus juga akan menjadi penentu perencanaan pengembangan wilayah mereka sendiri. Penentuan dan penegasan batas daerah menjadi penting karena sesuai dengan kegunaannya yaitu: meminimalisir terjadinya konflik batas, sebagai rujukan kerja yang akan datang, tertib administrasi pemerintahan, perhitungan fiskal daerah, kepastian hukum dan yurisdiksi pemerintah daerah, rencana tata ruang tepat sasaran, memberi keyakinan (nilai tambah) kepada investor, dan implementasi good \& clean governance.

Dalam Rencana Pembangunan Jangka Menengah Daerah (RPJMD) Kabupaten Enrekang tahun 2014-2018 kebijakan umum dan program pembangunan daerah di Kabupaten Enrekang memiliki sasaran yaitu Terwujudnya kesadaran partisipasi masyarakat dalam perencanaan pembangunan. Manfaat pemetaan sangat berkaitan dengan proses perencanaan pembangunan suatu wilayah. Dengan kebijakan umum yaitu penyediaan dokumen perencanaan yang dipersyaratkan dalam peraturan perundang-undangan. 
Tabel 1. Kebijakan Umum dari Program Pembangunan Daerah

\begin{tabular}{|c|c|c|c|c|c|c|c|c|c|}
\hline 3 & $\begin{array}{l}\text { Terwujudnya } \\
\text { kesadaran } \\
\text { partisipasi } \\
\text { masyarakat } \\
\text { dalam } \\
\text { perencanaan } \\
\text { pembangunan }\end{array}$ & $\begin{array}{l}\text { Mengoptimalkan } \\
\text { peran serta } \\
\text { masyarakat secara } \\
\text { aktif sebagai mitra } \\
\text { kerja pemerintahan } \\
\text { dalam perencanaan } \\
\text { pembangunan } \\
\text { daerah }\end{array}$ & $\begin{array}{l}\text { Penyediaan } \\
\text { dokumen } \\
\text { perencanaan yang } \\
\text { dipersyaratkan } \\
\text { dalam peraturan } \\
\text { perundang- } \\
\text { undangan }\end{array}$ & $\begin{array}{l}\text { Rasio ketepatan } \\
\text { waktu penyelesaian } \\
\text { Dokumen } \\
\text { Perencanaan dan } \\
\text { penganggaran } \\
\text { pembangunan } \\
\text { daerah (RKPD, KUA- } \\
\text { PPAS, RKA, APBD } \\
\text { dan DPA-SKPD) }\end{array}$ & $40 \%$ & $100 \%$ & $\begin{array}{l}\text { Program } \\
\text { perencanaan } \\
\text { pembangunan } \\
\text { daerah }\end{array}$ & $\begin{array}{l}\text { Perencanaan } \\
\text { Pembanguna } \\
\mathrm{n}\end{array}$ & Bappeda \\
\hline
\end{tabular}

Sumber: RPJMD Kabupaten Enrekang 2014-2018

\section{Hasil Kegiatan}

\subsection{Persiapan Kebutuhan Data Terkait Kegiatan Penyuluhan dan Pendampingan}

\subsection{Penyiapan Peta}

Dalam pelaksanaan penyuluhan dan pendampingan maka diperlukan data yang terkait dengan kegiatan penyluhan dan pendampingan. Salah satu data yang diperlukan berupa peta dasar. Peta dasar bertujuan untuk ditunjukkan kepada peserta mengenai karakteristik lokasi yang akan dibahas pada kegiatan tersebut, dalam hal ini Peta Guna Lahan Kecamatan Anggeraja serta Peta Kawasan Hutan Kecamatan Anggeraja.
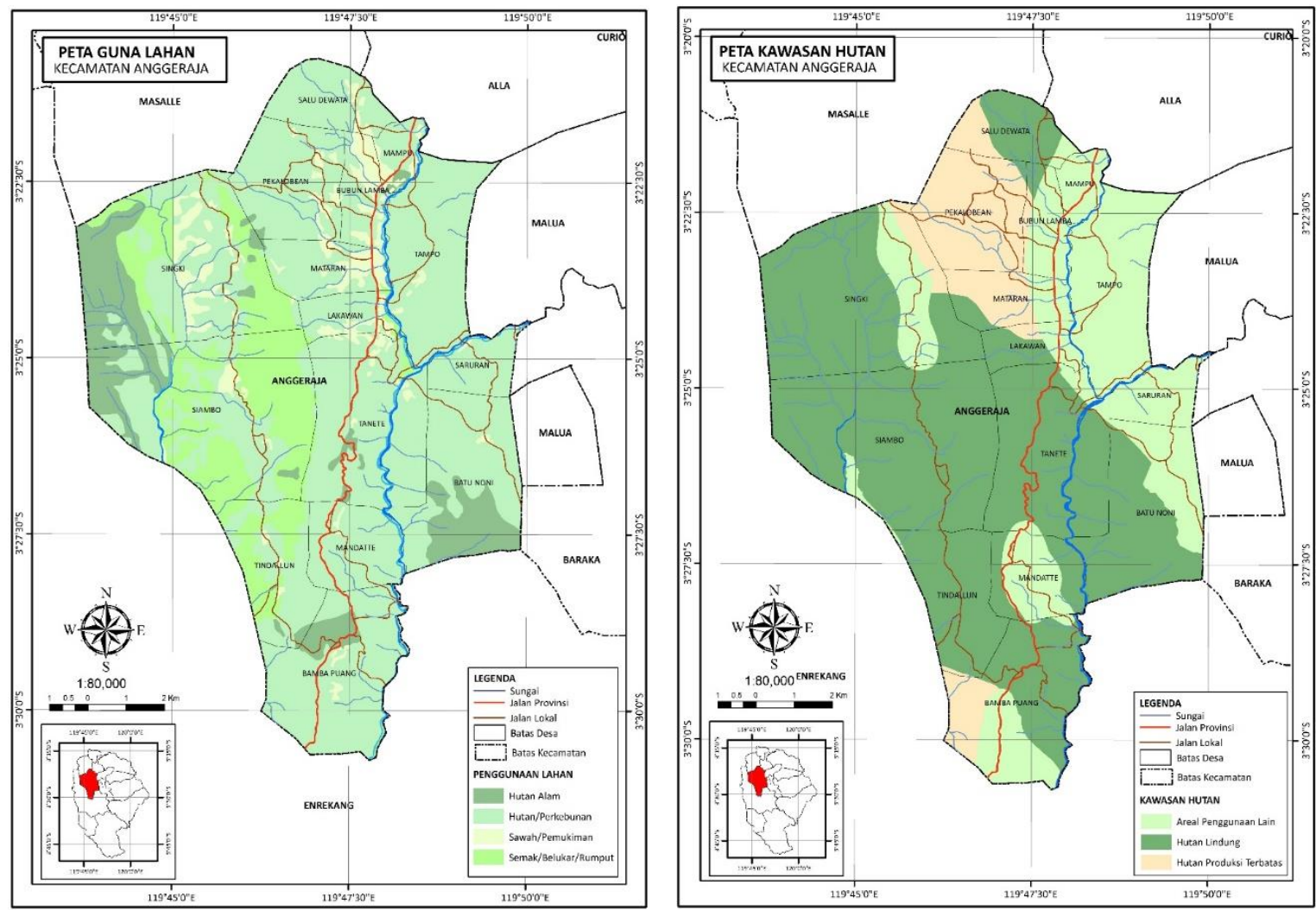

Gambar 1. Peta Guna Lahan dan Peta Kawasan Hutan Kecamatan Anggeraja Kabupaten Enrekang 
Peta kawasan hutan Kecamatan Anggeraja Kabupaten Enrekang mengambarkan fungsi kawasan hutan di Kecamatan Anggeraja yang didominasi oleh kawasan hutan lindung. Peta tersebut diolah dengan alat analisis GIS (Goegrafy Information System) yaitu arcGis 10.1. Data diolah sehingga menghasilkan data luas kawasan hutan lindung di Kecamatan Anggeraja berdasakan Desa. Berikut adalah hasil pengolahan data spasial kawasan hutan lindung Kecamatan Anggeraja.

Tabel 2. Luas Kawasan Hutan setiap desa di Kecamatan Anggeraja.

\begin{tabular}{rlcrrr}
\hline No & & \multicolumn{3}{c}{ Luas (Ha) } \\
\cline { 3 - 6 } & & Hutan Lindung & $\begin{array}{c}\text { Hutan Produksi } \\
\text { Terbatas }\end{array}$ & \multicolumn{2}{c}{$\begin{array}{c}\text { Lreal Penggunaan } \\
\text { Lain }\end{array}$} \\
\hline 1 & Siambo & 2021.75 & 0 & 46.91 \\
\hline 2 & Singki & 1484.21 & 112.53 & 360.56 \\
\hline 3 & Tanete & 1195.61 & 0 & 92.13 \\
\hline 4 & Batu Noni & 738.22 & 0 & 394.26 \\
\hline 5 & Tindalun & 707.26 & 7.27 & 6.28 \\
\hline 6 & Bambapuang & 627.88 & 202.98 & 344 \\
\hline 7 & Salu Dewata & 296.5 & 416.18 & 33.21 \\
\hline 8 & Mandatte & 205.94 & 0 & 304.32 \\
\hline 9 & Lakawan & 146.57 & 27.84 & 95.63 \\
\hline 10 & Mataran & 59.99 & 247.56 & 121.74 \\
\hline 11 & Bubun Lamba & 32.3 & 30.33 & 253.81 \\
\hline 12 & Pekalobean & 11.32 & 770.33 & 0 \\
\hline 13 & Mampu & 0 & 0 & 192.3 \\
\hline 14 & Saruran & 0 & 0 & 306.72 \\
\hline 15 & Tampo & 0 & 0 & 6.28 \\
\hline
\end{tabular}

Tabel diatas digunakan sebagai bahan kegiatan penyuluhan untuk memaparkan luas hutan lindung di Kecamatan Anggeraja. Dimana data tersebut merujuk pada Peraturan Daerah Kabupaten Enrekang No.14 Tahun 2011 tentang Rencana Tata Ruang Wilayah Kabupaten Enrekang Tahun 2011-2030, diatur mengenai Rencana Pola Ruang Kabupaten Enrekang yang mencakup kawasan budidaya dan kawasan lindung.

\subsection{Survei}

Pada kegiatan ini juga dilakukan survei untuk meninjau keadaan kawasan di lapangan. Kegiatan survei dilakukan sebagai upaya meninjau data pemetaan yang telah dilakukan sekaligus melakukan observasi pada batas kawasan budidaya dan kawasan lindung untuk meninjau apakah fungsi kawasan berubah atau tetap pada fungsi yang seharusnya. Kegiatan ini dilakukan sebagai langkah peninjauan awal sebelum dilakukannya penyuluhan di lokasi tersebut. Kegiatan survei dilakukan dengan menggunakan GPS dan alat survei lainnya. 

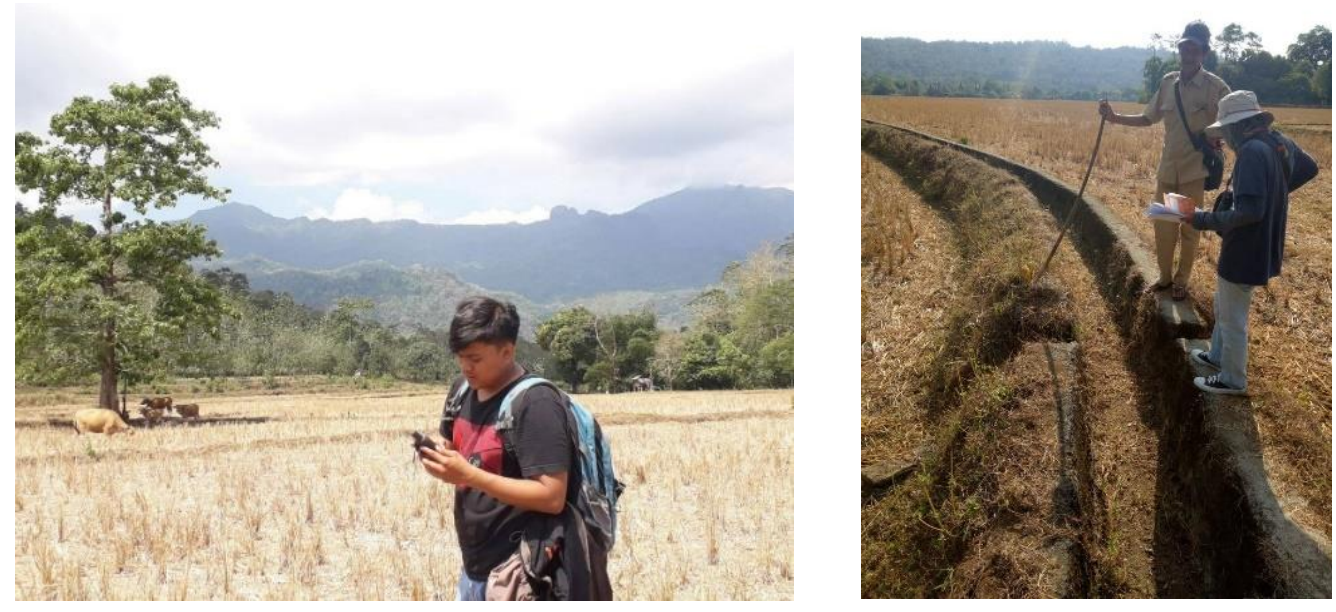

Gambar 2. Kegiatan survei

\subsection{Koordinasi Kegiatan Kepada Pihak Mitra}

Kegiatan Kunjungan Rektor Universitas Hasanuddin ke Kabupaten Enrekang sebagai rangkaian kegiatan Dies Natalis Unhas menjadi wadah untuk mengenalkan kegiatan pengabdian masyarakat kepada mitra. Kegiatan berupa pameran poster rencana pengabdian masyarakat yang selanjutnya dilakukan koordinasi dengan pihak mitra mengenai waktu dan konsep pelaksanaan kegiatan.

Kegiatan ini diawali dengan Rektor Unhas dan Bupati Enrekang yang bersama-sama meninjau dan melihat hasil-hasil penelitian di Kabupaten Enrekang yang telah dilaksanakan maupun kegiatan pengabdian masyarakat yang akan dilaksanakan. Kegiatan ini dilakukan dalam upaya memamerkan hasil karya Unhas kepada Pemerintah Kabupaten Enrekang dan begitupun sebaliknya.
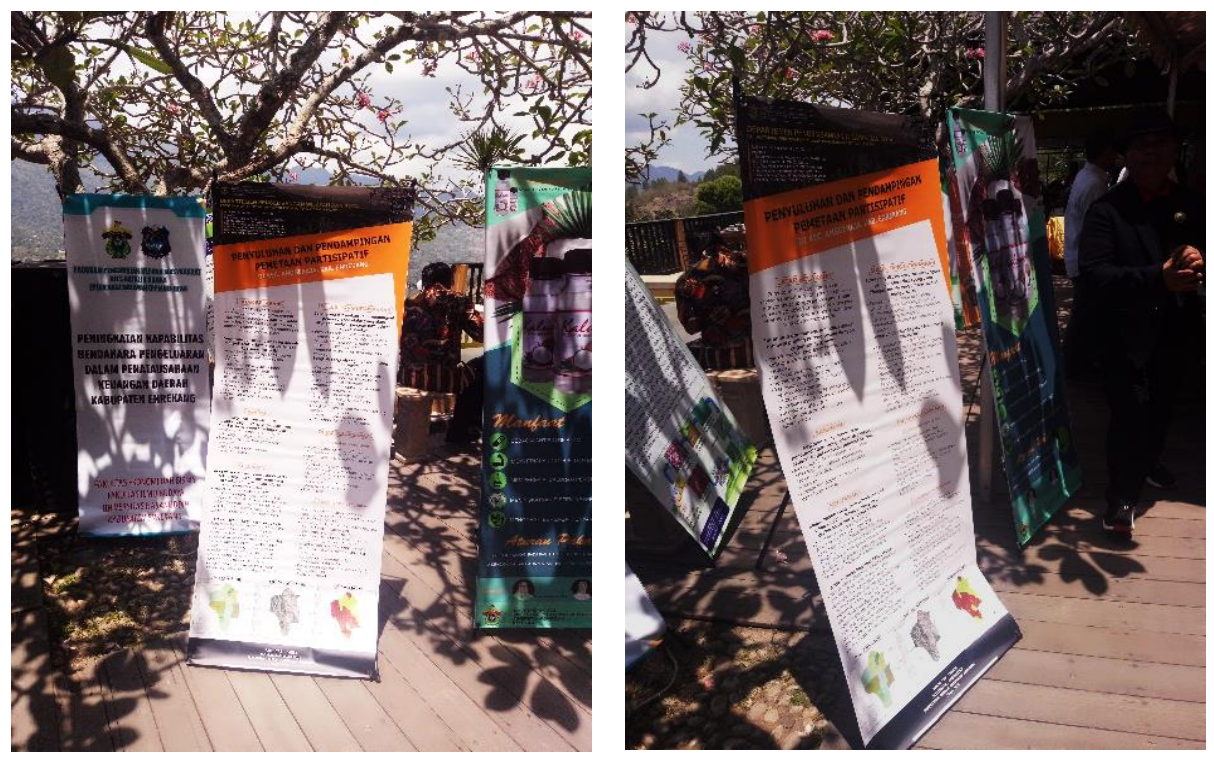

Gambar 3. Dokumentasi Kegiatan Pameran 

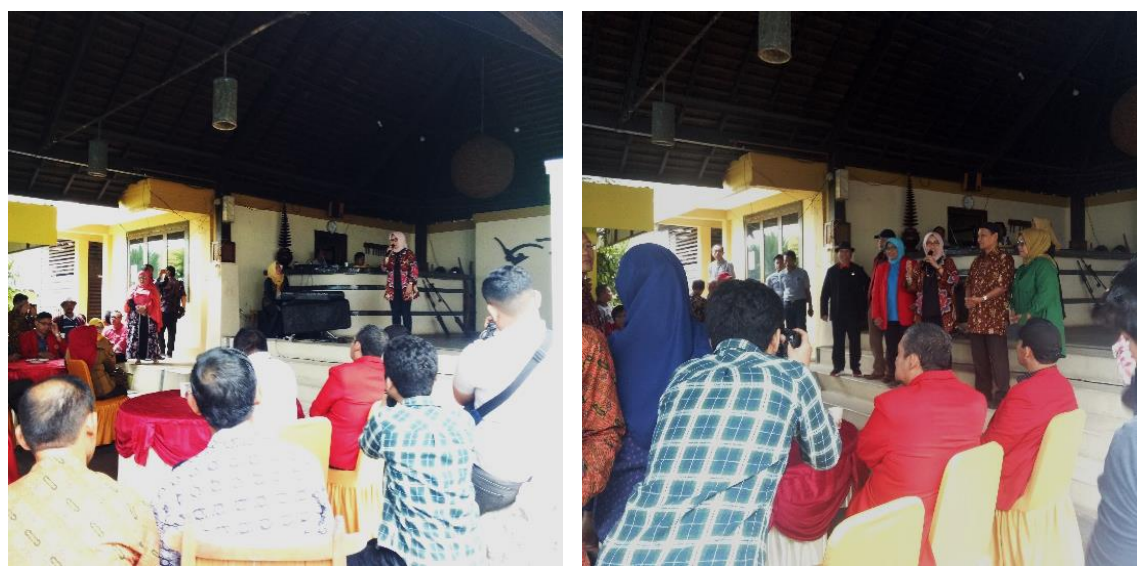

Gambar 4. Kegiatan Pameran

\subsection{Penyusunan Bahan FGD (Focus Grup Discussion)}

Penyusunan bahan Focus Group Discussion (FGD) dimana masalah yang dihadapi oleh pihak mitra maupun yang ada dilapangan dikaitkan dengan kajian teori dan implementasi kebijakan pemerintah Kabupaten Enrekang sehingga ditemukan prinsip-prinsip pemecahan masalah yang dihadapi baik dari pihak mitra maupun yang ada dilapangan terkait kawasan hutan lindung khususnya di Kecamatan Anggeraja.

\section{PERMASALAHAN}

Kondisi kabupaten Enrekang yang saat ini memperlihatkan kawasan lindung yang cukup luas. Namun, diketahui masyarakat masih kurang memiliki pengetahuan informasi geospasial mengenai tapal batas kawasan.

\section{Persoalan prioritas yang realistis untuk} diselesaikan bersama

1) Adanya kejelasan pengetahuan bagi masyarakat setempat mengenai informasi spasial di wilayahnya.

2) Kebijakan pemerintah Kabupaten Enrekang mengenai status kawasan dan batasannya.

Gambar 5. Permasalahan yang dihadapi

\section{SOLUSI YANG DITAWARKAN}

1) Persoalan kekurangan kompetensi pemetaan dilakukan dengan metode penyuluhan, pendampingan, dan/atau training-training bermodul.

2) Pembuatan dokumen pemetaan batas kawasan.

\section{Langkah-Langkah Kegiatan} Solusi yang Ditawarkan

1) Penyuluhan tentang kebijakan, pemanfaatan serta pembuatan peta, selama 3 jam, dengan target peserta yaitu masyarakat setempat.

2) Pendampingan dalam penyusunan dokumen pemetaan.

Gambar 6. Solusi yang ditawarkan

\subsection{Penyuluhan dan Pendampingan Pemetaan Partisipatif}

Kegiatan penyuluhan dan pendampingan pemetaan dilaksanakan di Ruang pola kantor Kecamatan Anggeraja dan dibuka secara langsung oleh Camat Anggeraja. Kegiaatan dihadiri 
masyarakat dari beberapa desa di Kecamatan Anggeraja khususnya desa yang kawasannya didominasi oleh kawasan hutan lindung.

Kegiatan ini diawali dengan memaparkan hasil riset dan kajian pihak tim pengabdian masyarakat kepada masyarakat yang hadir dalam kegiatan tersebut mengenai Batasan dan fungsi kawasan di Kecamatan Anggeraja. Kemudian kegiatan dilanjutkan dengan sesi diskusi untuk memberikan peluan bagi masyrakat setempat menyampaikan aspirasi dan pendapatnya mengenai hasil riset yang telah dipaparkan.
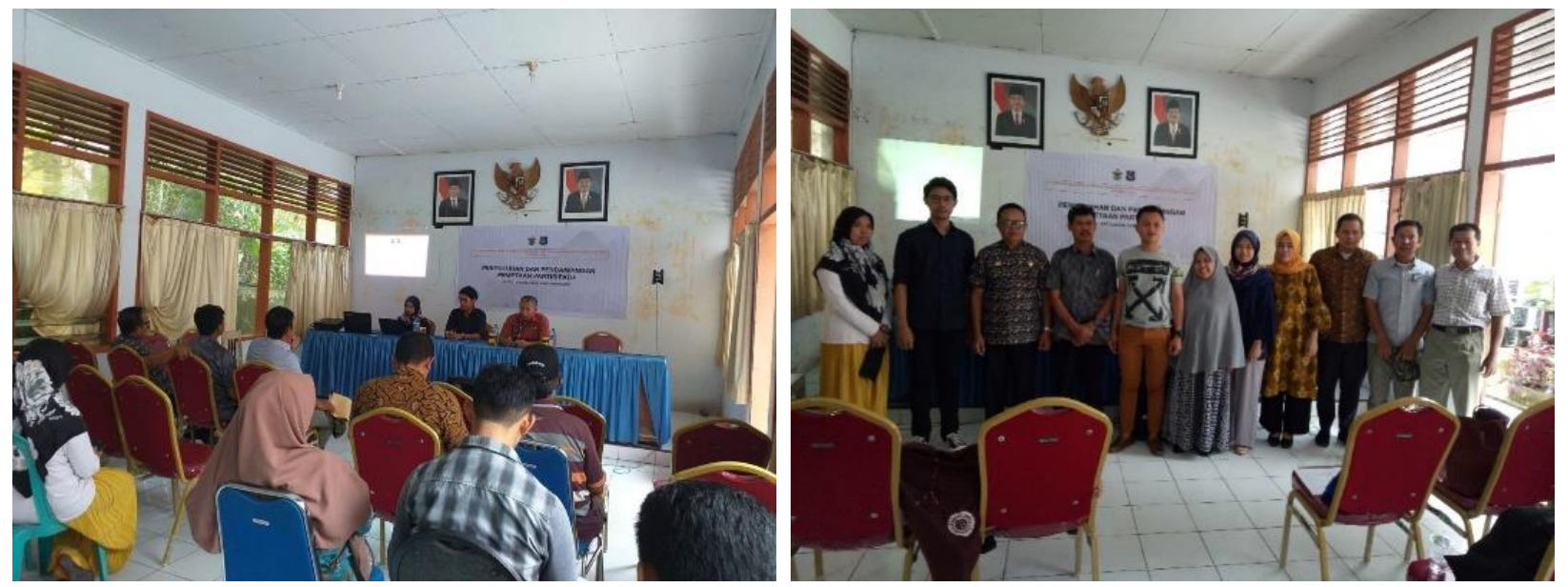

Gambar 7. Kegiatan Penyuluhan dan pendampingan pemetaan partisipatif

Kegiatan selanjutnya dilakukan pemberian materi pemetaan pada peserta. Peserta yang hadir terdiri dari unsur pemerintahan (dari kecamatan dan desa) hingga tokoh masyarakat yang memahami mengenai batas-batas desa. Materi atau topik yang dibahas dalam pertemuan ini, antara lain:

(1) Diskusi untuk mengidentifikasi/groundcheck terkait dengan penggunaan lahan dalam hal ini tentang Kawasan hutan serta batas desa.

(2) Identifikasi wilayah desa melalui media citra satelit serta data hasil survey awal yang meliputi: batas desa, batas kawasan lindung, dan penjelasan hasil pengamatan lapangan.

Berdasarkan hasil diskusi dan feedback peserta penyuluhan dilakukan Analisa pemetaan kawasan hutan di masing-masing desa di Kecamatan Anggeraja. Berikut hasil pemetaan Kawasan hutan di delapan

desa

yang

memiliki

Kawasan

hutan. 

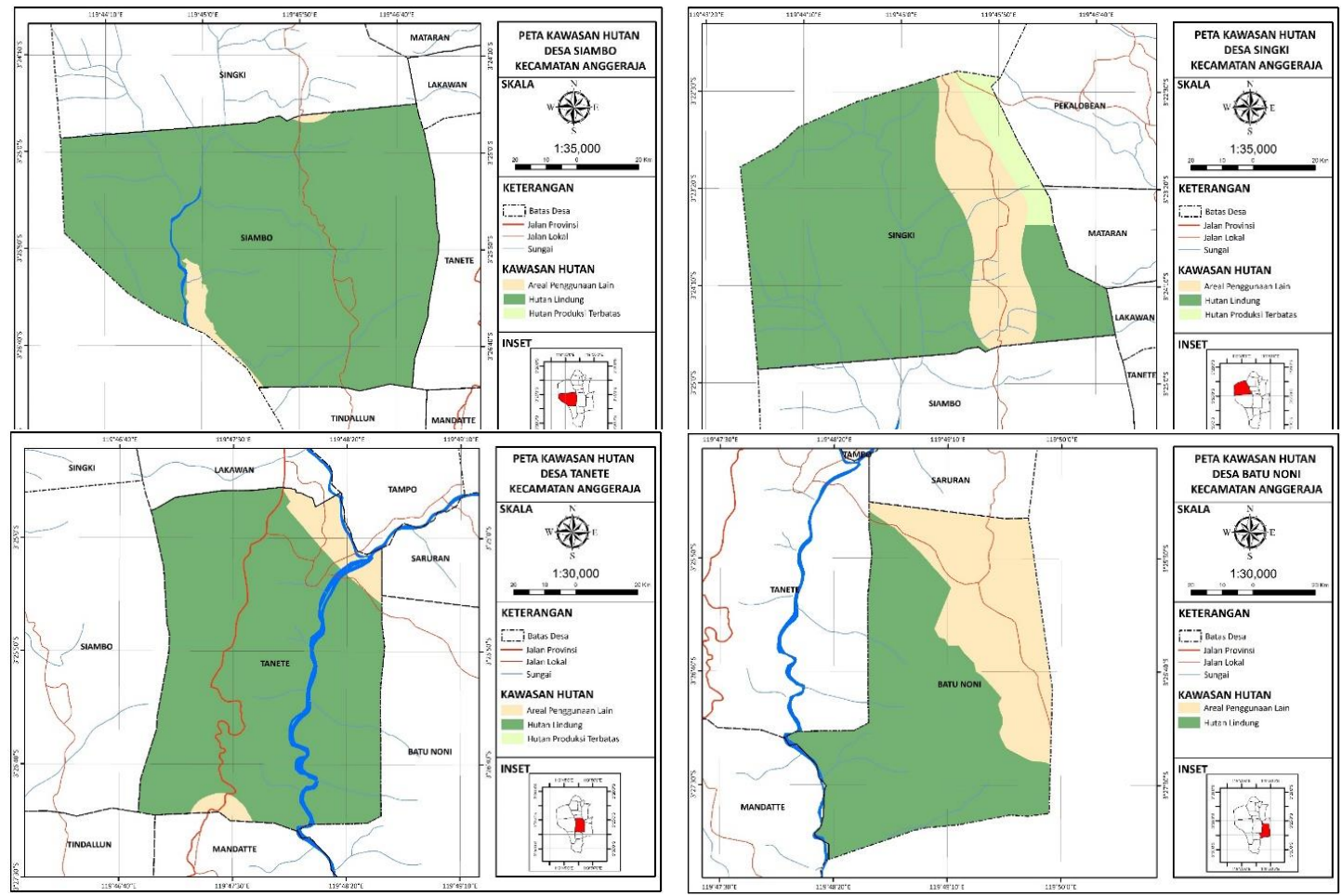

Gambar 8. Peta Kawasan hutan Desa Siambo, Desa Singki, Desa Tanete, dan Desa Batu Noni
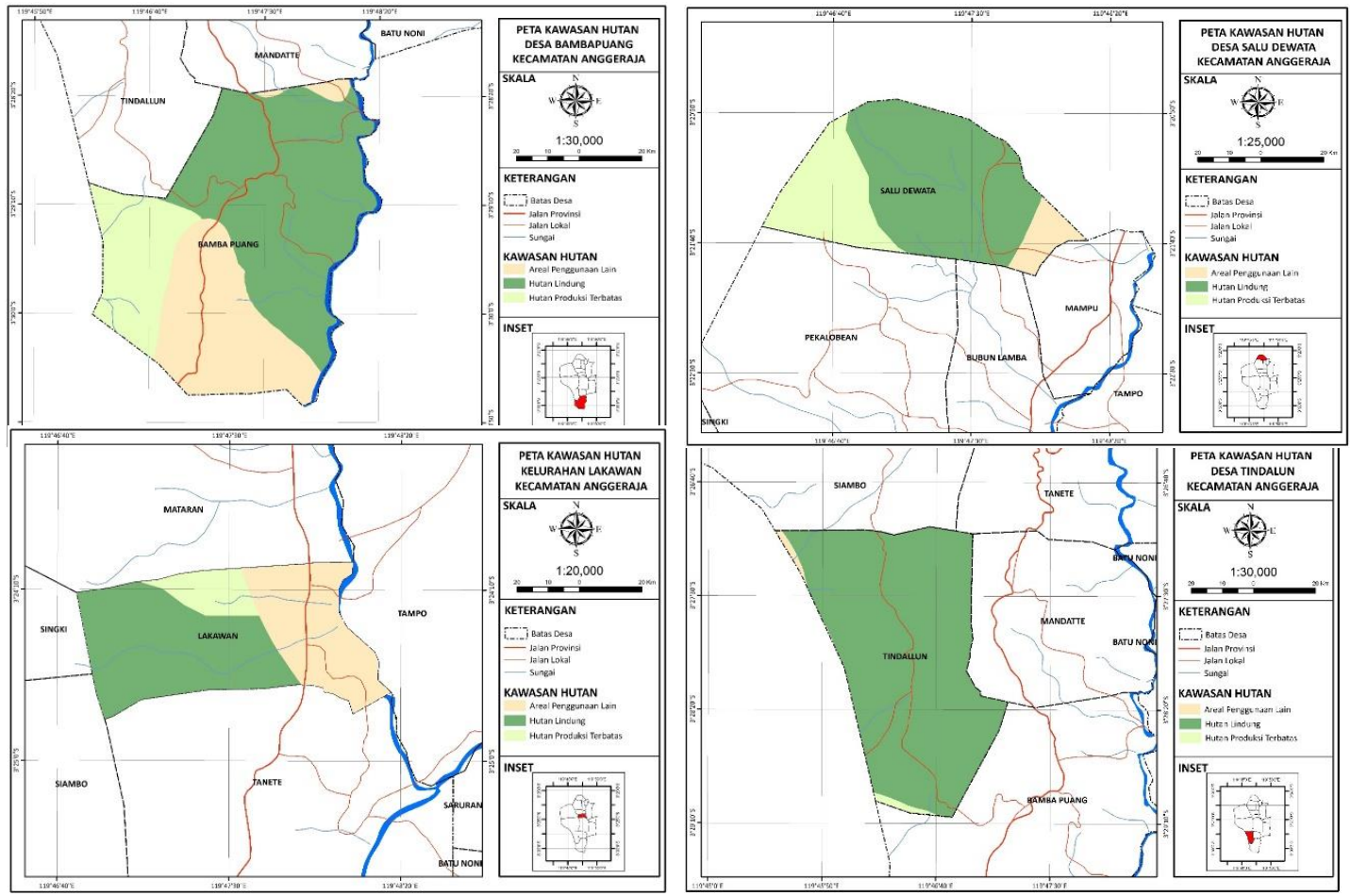

Gambar 9. Peta Kawasan Hutan Desa Tindalun, Desa Bambapuang, Desa Salu Dewata, dan Desa Lakawan 


\section{Kesimpulan}

Dari hasil pemetaan diatas dapat terlihat hampir seluruh Kawasan di areal masing-masing desa di delapan desa tersebut diatas memiliki Kawasan hutan lindung dan Desa Siambo merupakan desa yang memiliki Kawasan lindung terluas yang seyogyanya dilestarikan bersama masyarakat. Penting bagi masyarakat untuk tahu dan tidak melakukan alih fungsi lahan menjadi Kawasan area produktif. Dengan adanya kegiatan penyuluhan dan pendampingan ini diharapkan agar masyarakat lebih tahu dan peka dengan kondisi areal lindung di sekitarnya dan mengenal batas Kawasan wilayah atau daerahnya untuk meminimalisir/mencegah alih fungsi lahan.

\section{Ucapan Terima Kasih}

Ucapan terima kasih kepada seluruh kepala desa di Kecamatan Anggeraja dan jajaran staf kecamatan yang telah memfasilitasi pelaksanaan kegiatan ini serta turut serta mendorong keaktifan masyarakat dalam kegiatan ini.

\section{Daftar Pustaka}

Badan Pusat Stratistik Kecamatan Anggeraja Kabupaten Enrekang (BPS Enrekang), (2017). Peraturan Pemerintah nomor 78 tahun 2007 tentang Tata Cara Pembentukan, Penghapusan dan Penggabungan Daerah

Undang-Undang Dasar Tahun 1945.

RPJMD Kabupaten Enrekang 2014-2018. 